\title{
LOAD SENSITIVITY ANALYSIS FOR A FLOATING WIND TURBINE ON A STEEL SEMI-SUBMERSIBLE SUBSTRUCTURE
}

\author{
Kolja Müller \\ University of Stuttgart \\ Stuttgart, Germany
}

\author{
Ricardo Faerron Guzman \\ University of Stuttgart \\ Stuttgart, Germany
}

\author{
Po Wen Cheng \\ University of Stuttgart \\ Stuttgart, Germany
}

\author{
Josean Galván \\ Tecnalia R\&I \\ Derio, Bizkaia, Spain
}

\author{
Miren J. Sánchez \\ Tecnalia R\&I \\ Derio, Bizkaia, Spain
}

\author{
Raúl Rodríguez \\ Nautilus F.S. \\ Derio, Bizkaia, Spain
}

\author{
Andreas Manjock \\ DNV GL \\ Hamburg, Germany
}

\begin{abstract}
The site-specific load verification for floating offshore wind turbines requires the consideration of the complex interaction of the different system components and their environment. Sensitivity analyses help reducing the simulation amount for both fatigue and ultimate load analysis significantly by highlighting relevant load parameters and increase the understanding for the system behavior in its real environment. Aligned with work in the H2020 project LIFES50+, this study investigates different approaches for global sensitivity analysis using quasi-random sampling for the independent variables.

Two different load case groups are analyzed: (1) fatigue loads during power production, (2) ultimate loads during power production and severe sea state. The considered system is the public DTU 10MW turbine's rotor-nacelle assembly, installed on the public NAUTILUS-10 floating structure. Load simulations are performed by using FAST v8. Simulations are set up based on the LIFES50+ Site B (medium severity). A comparison is made to a similar study with a different platform (Olav Olsen semi-submersible) in order to observe if similar conclusions can be reached for the different floater types.
\end{abstract}

Keywords: floating wind, global sensitivity analysis, sampling, probabilistic design, NAUTILUS-10, LIFES50+

\section{INTRODUCTION}

Floating offshore wind turbines (FOWT) promise large scale and low-cost energy generation due to increased distance to the shore. In order to drive down the system costs, standardized, fast and accurate processes need to be established in the design. This is also the case for the site-specific load verification of a considered system.
Load cases are an inherent part in the wind turbine standards and define the specific design load criteria for the structural design according to defined classes of environmental impacts. These generic external conditions describing wind, waves, currents, etc. and their related meteorological parameters in different classes of severeness and allow the calculation of reproducible and comparable load sets. The definition of extreme events - in wind industry standards a recurrence period of 50 years has been established - in combination with partial safety factors reflect a generally accepted safety level which enables a safe energy production during life time, typically 20 years. The intention of the load case definitions is to cover all load relevant situations within the designated life time of the system. These are basically normal operation, extreme events, failure modes and grid impacts in combination with operation and stand-still conditions. In line with the growth of turbine size, structural elasticity and complexity of modern wind turbines the load case definitions in international standards such as the IEC61400 (e.g. [1]) series or DNV GL standards (e.g. [2]) have been extended continuously. This was done e.g. by replacing stationary wind conditions by turbulent wind fields and introducing extrapolation methods for the determination of extreme load levels. A full load case setup for final design or for certification of a floating wind turbine according to above mentioned standards could easily reach $10^{4}$ different load case variations. Such a setup includes e.g. a complete representation of the wind and wave spectra with all relevant combinations and directionalities. This procedure ensures that all situations with a potential to generate critical design loading are covered by the load case setup.

However, a sensitivity analysis does not require absolute design load values and focusses more on qualitative results and comparability of the simulated data. Therefore, it is reasonable 
to apply a sub set of the complete standard load cases definition. Within this study, three typically dimensioning load cases for floating wind turbines have been selected for the statistical analysis. The selected load cases comprise fatigue load cases during normal operation between cut-in and cut-out wind speed (DLC1.2) and two extreme load cases. The extreme situation of power production during a severe sea state (DLC1.6) and idling during a 50-year storm event (DLC6.1) generally produce critical loads for the rotor-nacelle assembly, the tower, the floater and the station keeping system. The results of two of these load cases (DLC1.2 and DLC1.6) are presented in this study.

Aligned with work performed in deliverable D7.7 of the H2020 project LIFES50+, this study supports the definition of the numerical setup in the design of floating offshore wind turbines. Such numerical set up is done in order to calculate the ultimate loads (maximum loads) and fatigue loads (load amplitude driven) that the turbine might experience during its lifetime. The complexity of the environmental conditions, however, would make it a very time consuming task to be able to simulate every single combination of possible wind and wave simulation inputs, which might include wind speed, turbulence intensity, shear, yaw misalignment, significant wave height, peak wave period, wind/wave misalignment, currents, among others. Furthermore, due to the geometry of the floating platform and its hydrodynamic interaction with the sea, certain characteristic unique excitation frequencies will exist, which under different environmental conditions, might lead to excitations. This makes every platform different.

Sensitivity analysis (SA) methods help to investigate which environmental parameters are important in the design stages of the turbine. A well-defined procedure for SA supports the determination of significant parameters with significant influence on the response: in this case, the loads experienced by the turbine. This work will elaborate on the global sensitivity analysis method.

\section{CONSIDERED SETUP}

\subsection{Considered system}

The Floating Offshore Wind Turbine (FOWT) object of study (NAUTILUS-DTU10 MW FOWT) is composed by the DTU 10 MW Reference Wind Turbine [3], [4] and the NAUTILUS floating support structure [5], [6] (NAUTILUS-10), designed for a site representative of moderate conditions [7].

The NAUTILUS concept is a semi-submersible floater with four columns, a squared ring pontoon connecting them at their lower ends, a X-shaped main deck consisting of four rectangular shaped connections between column's upper ends and an embedded transition piece. The transition piece connects the tower base with the upper part of the main deck, so above the water zone. The wind turbine is located centred relative to the columns. The substructure is moored to the seabed using four conventional catenary steel chain mooring lines arranged in a symmetrical configuration. NAUTILUS-DTU10 MW FOWT is controlled by the DTU Wind Energy Controller [8] and NAUTILUS-10 Platform Trim System (PTS).

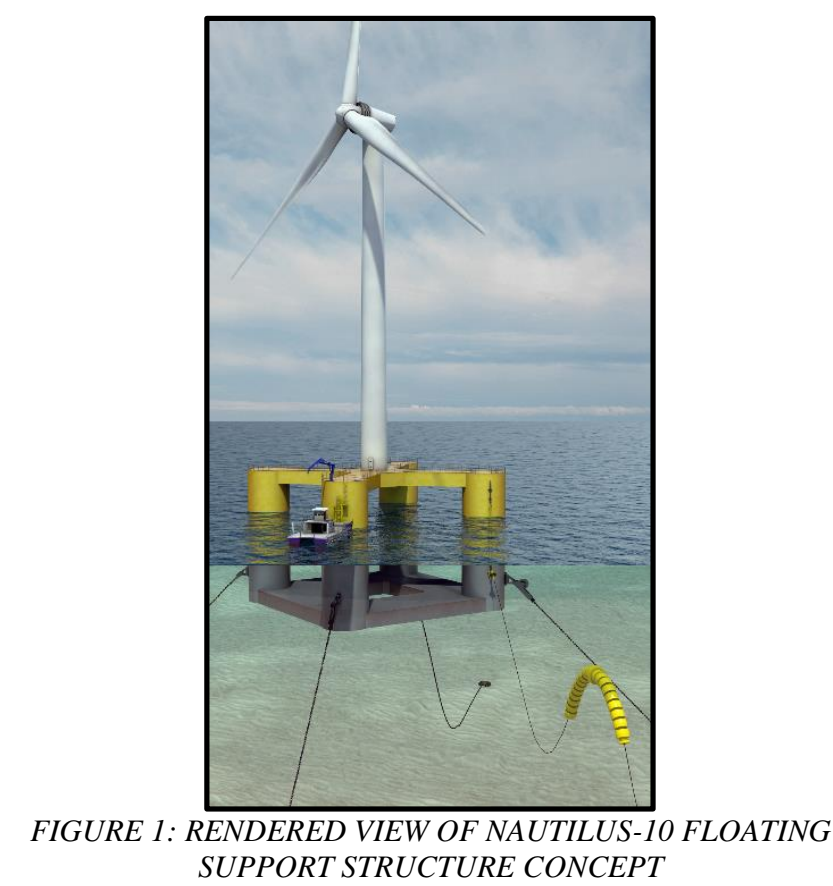

The four columns provide buoyancy forces to support the turbine and sufficient water plane area for the restoring forces to achieve the required static and dynamic stability. The ring pontoon is filled with passive ballast to lower the centre of gravity and to improve the stability. A closed-loop active ballast system has been designed to mitigate wind-induced thrust forces, restoring the system to optimal efficiency following changes in wind velocity and direction and keeping the verticality of the tower. The PTS pumps sea water in or out independently into each of the individual columns to adjust the draft (target floater air gap) and to compensate for the mean wind thrust loading on the turbine rotor and substructure.

\subsection{Considered environment}

Reference environmental conditions are used for the simulations of the turbine. These are taken from the LIFES50+ Project. The wind and wave conditions analysed are representative of those in a medium severity site. The data is taken from the Gulf of Maine, which is along the east coast in the United States of North America. The site is located in the North Atlantic Ocean, about $25 \mathrm{~km}$ at the southwest of Monhegan Island and $65 \mathrm{~km}$ east from Portland, Maine. The representative site has a constant water depth of $130 \mathrm{~m}$. The wind speed distribution is characterized by a Weibull scale coefficient of 6.2 and a shape coefficient of 1.7 , as derived by a measurement buoy. More information on the site and environmental data are specified in [9]

\subsection{Considered simulation setup and applied models}

The NAUTILUS-DTU 10MW FOWT coupled dynamics has been analysed in time domain to capture problem nonlinearities and 
interaction between the physics involved. With this objective, a numerical model has been implemented using FAST v8.16 open source code which is developed and distributed by the National Renewable Energy Laboratories (NREL) of U.S [10], [11]. The numerical model employed can be publicly accessed and downloaded [12].

The system dynamics and elastodynamics are represented by a combined multibody and modal approach implemented in ElastoDyn module [13]. The proposed model accounts for 21 Degrees Of Freedom (DOFs), where the flexible blades make use of 9 DOFs (most 3 relevant mode shapes by each blade) and the flexible tower accounts for 4 DOFs. The floating platform is modelled as a rigid body due to the compact design and high structural stiffness of the NAUTILUS-10 semi-submersible and it is represented by six DOFs which are limited due to the restoring effects of the station-keeping system. The drivetrain DOFs are its torsional flexibility and its rotational motion.

The rotor-nacelle-assembly (RNA) aerodynamics are captured by traditional Blade-Element Momentum (BEM) theory and the common corrections included by AeroDyn [14]. Although the tower and floating platform aerodynamics can have significant impact on the FOWT dynamics, both have been neglected in the model employed.

As it is previously stated, the NAUTILUS-DTU10 MW FOWT is controlled by the wind turbine (WT) controller [8] and the NAUTILUS-10 platform trim system (PTS) that drives the sea water ballast distribution. While the WT controller dynamics has been considered and modelled by means of a tuned controller defined for this floating concept; the ballast distribution has been modified for each wind speed and direction considered but it has been maintained constant through the Load Case (LC) simulation, similar to the assumption adopted for the nacelle yaw controller whose large period does not influence the dynamic part of the response.

Hydrodynamics of the semisubmersible have been modelled relying second order (Newman's approximation) potential flow solution complemented with linear and quadratic damping terms related to the floater absolute speed in order to capture the viscous effects. The additional hydrodynamic damping (AHD) approach is much more quick than a Morison element model, but when implemented inside HydroDyn [11], presents the drawback of neglecting the sea current actions.

Finally, mooring dynamics has been modelled using MoorDyn code [15] which accounts for inertial and viscous effects. The model includes an internal damping and a line-to-seabed contact model that does not consider the friction.

Further information related to the numerical model is given in [5].

Periodic wind files have been used for turbulent wind simulations longer than 10 minutes. This is because current memory RAM storage is limited, and 3 hour wind files range in the size of gigabytes. It is noted that the cross section of the wind file should be large enough to cover the entire rotor for all the range of motions that the platform has in surge, sway and heave.

\section{SENSITIVITY ANALYSIS}

Even though most variables defining the response of a given system are prone to uncertainty and hence also influence the result, typically only a subset of variables is of major significance for the response (Pareto principle).

SA investigates the impact or effect of the uncertainty of a number of independent model input variables or parameters (e.g. wind speed) on the uncertainty of the model output (e.g. maximum loading). In this way, a well-defined procedure for SA supports the determination of the significant parameters (i.e. with significant influence on the response). The designer may then neglect insignificant parameters (by using a fixed, conservative value) and use significant values as independent variables in the probabilistic design. In this way, SA-procedures support a time- and cost-efficient design process. Next to the probabilistic design, SA may also support model development, verification, calibration, model identification and mechanism reduction [16].

For simulation models, a general SA workflow is as follows [17]: In a first step, a sampling of the input parameters is defined which defines the baseline set of input-output samples used for the SA. An efficient (i.e. most possible information for simulation effort) sampling procedure is important, if the inputoutput relationship is complex. Then, a direct calculation of the model sensitivities is not possible and they are approximated numerically by surrogate models or representative values. In the next step, the model is evaluated. In this work this means the running of FAST simulations. Also, the post-processing of the results is performed, so that for each combination of input parameters one output parameter such as damage equivalent load (DEL) or maximum loads are available. With the resulting set of input-output samples, the SA may be performed. Following [17] and [16], SA can be defined by its scope, sampling method and means of post-processing.

\section{Scope: screening, local and global sensitivity analysis}

In particular, for numerical models for which evaluation is expensive, so-called screening experiments provide a cheap solution to identify a relevant subset of input parameters, which controls most of the variability of the output. Screening experiments only help to rank the different input parameters but do not give a correct quantitative value of each of the parameters influence.

As part of local sensitivity analysis, the independent variables are varied around a fixed value (e.g. mean), and the partial derivatives of the investigated model around an operating point may be obtained [18]. However, the determination of higher order dependencies between input and output (in particular combined effects of input variables) is not possible. Also, the obtained response is depending on the chosen center and variation points [19] and is typically assumed to be linear [16]. Global sensitivity analysis overcomes the limitation of investigating only the variation around an operating point by varying all input parameters at the same time. Compared to screening procedures, it also allows the precise calculation of the contribution of the input parameters variation to the output 
variability. Even though the global approach is quite flexible, it still requires the definition of the input variability space [17], which is important for the outcome of the analysis.

In this work, the environmental conditions wind speed, wave height, wave period, wind and wave directions and water height are assumed to be the most relevant independent parameters. This is a fairly low number $(<10)$, which is why a GSA approach is found most feasible. In a general setting, screening methods would be used in an initial step to determine the relevant parameters.

\section{Sampling: definition of evaluation points}

The sampling strategy essentially may follow two different strategies. The first option is to vary only one input variable at a time while keeping all other inputs fixed (this means a variation around working point, is often referred to One-factor-at-a-time and is used for local SA). The second option is to vary all input variables simultaneously for each new model evaluation (this means a variation across a predefined input space or all-factorsat-a-time and is used for screening and global SA).

Varying all factors at the same time allows the evaluation of the effect of single input variables as well as their joint influence due to interaction. This may be done in different ways via design of experiment or sampling based, possibly taking into account the probability distribution and range of the input parameters [16].

Only the variation of all factors at the same time is considered here, because global sensitivity analysis is the focus of this work. In addition, a sample-based definition of the evaluation points is performed, using quasi-random sampling as described in [20]. This is done due to the complex expected model response, which may not be detected from simpler design of experiments [21].

\section{Post-processing: Means of analyzing the results}

Post-processing the acquired samples may be done either qualitative using visual inspection (e.g. scatter plots) or quantitative based on numeric importance measures. While visual inspection may help to get an intuitive overview, it is unlikely to be of great support if the number of variables or evaluations is increased (i.e. this work focuses on 3 different load cases, 3 different locations 3 load ranges and 5 different variables, which results in 135 scatter plots). If the dimensionality of the analysis increases, quantitative measures help to provide precise measures of dependency, which may be used for ranking as well as identifying of the relative importance of the independent variables. Hence, quantitative inspection is of primary interest here due to large number of investigated relationships. This is also seen as a supporting measure for the engineer where to focus in the visual investigation, which is useful to determine simplified relationships and conservative assumptions.

A general distinction of SA is between important (parameters whose uncertainty propagates through the model resulting in output variability) and sensitive parameters (when there is a correlation between input and output parameters) [22]. The difference between important and sensitive is that important parameters are always sensitive, but sensitive parameters are not necessarily important, as some parameters have too little uncertainty for them to be important. Hence, not only the impact, but also the range under consideration play important roles in SA.

An example of the application of sensitivity analysis in the field of wind energy is [23], where a holistic, multi-step approach combining different depths of global sensitivity methods for the design of offshore wind turbines is proposed. The approach presented therein envelopes a four-step procedure to sequentially reduce the number of relevant independent variables. An initial baseline set of more than 100 independent variables is thus reduced to around 10 variables by stepwise application of (1) expert knowledge, (2) One-factor-at-a-time analysis, (3) regression analysis and finally (4) variance based analysis. A variance based sensitivity analysis of wind turbine power output is performed in [24], based on neural network surrogate and eight input parameters.

For this work, SA is of relevance to identify critical environmental conditions for different components of the FOWT, and support overall understanding for impact of environmental loads on the system (e.g. by defining simplified relationships). We focus on three load cases of major importance for floating wind turbines: Fatigue loads during power production and normal environmental conditions (DLC 1.2), ultimate loads during power production, normal wind environment and severe sea state (DLC 1.6) and ultimate loads during parked condition and extreme environment (DLC 6.1). Furthermore, we also focus on three load outputs as representative values for different components of a floating wind turbine: the blade root bending moment of one blade, the tower base resulting bending moment and the mooring line tension at the fairlead position. In order to investigate the impact on any mooring line, from each simulation the highest fairlead tension load was used as representative value for the mooring system. Only one step is performed in the SA, as it is assumed that a condensed set of candidates influencing the loading has already been determined. Three distinctive types of importance measures were found in [18], [23] and [16] for global SA which are found of interest to investigate in more depth for the present work. These are (1) (linear) correlation or regression based coefficients, (2) measures based on statistical tests and (3) variance based measures.

For the SA performed in this study, the following general assumptions and scope was taken into account:

- All inputs and outputs are assumed to be scaled to range $[0,1]$.

- $\quad$ Input parameters are uniformly distributed.

- Input parameters are mutually independent. This limitation may be overcome by using more advanced implementations, see e.g. [19] [25] [26].

- The terms surrogate model or surrogate is used for all results from curve fitting operations performed on simulation results. Typical alternative descriptions in the literature are meta-model and response surface. 
- The model response may be defined through a functional relationship of the form $y=f(\boldsymbol{x})=$ $f\left(x_{1}, x_{2}, \ldots, x_{n}\right)$

- All sensitivity measures are subject to uncertainty due to incomplete information basis $=>$ statistical analysis may be performed in order to assess the range of uncertainty. Uncertainty analysis of sensitivity measures is not part of this work.

In the following, the investigated sensitivity measures are presented in detail.

\subsection{Correlation coefficients}

This is considered the most well-known approach and very similar to regression analysis based sensitivity measures [17]. A correlation measure for 1D linear relationships between input parameter $x_{1}$ and output parameter $y$ for a given set of samples $\boldsymbol{x}_{1}=\left\{x_{1, i}, \ldots x_{1, n}\right\}$ and $\boldsymbol{y}=\left\{y_{i}, \ldots y_{n}\right\}$ may be calculated according to

1. the Pearson linear correlation coefficient

$$
\rho_{P}\left(\boldsymbol{x}_{1}, \boldsymbol{y}\right)=\frac{\sum\left(x_{1, i}-\overline{\boldsymbol{x}_{\mathbf{1}}}\right)\left(y_{i}-\overline{\boldsymbol{y}}\right)}{\sqrt{\sum\left(x_{1, i}-\overline{\boldsymbol{x}}\right)^{2} \sum\left(y_{i}-\overline{\boldsymbol{y}}\right)^{2}}}
$$

which has the range $[-1,1]$ and is known to be useful for the quantitative detection of linear relationships (i.e. $\rho_{\text {Pearson }}=0$ : no influence, $\rho_{P}=1$ positive linear correlation), but may not detect non-linear, nonmonotonic or interaction effects between input parameters. The calculation is very simple and fast.

2. Calculating the ranks of $\boldsymbol{x}_{\mathbf{1}}$ and $\boldsymbol{y}$ transforms any nonlinear but monotonic relationships into a linear relationship [27] With this, the Spearman rank correlation coefficient for detection of nonlinear monotonic relationships may be calculated:

$$
\rho_{S}\left(\boldsymbol{x}_{1}, \boldsymbol{y}\right)=1-\frac{6 \sum d_{i}^{2}}{n\left(n^{2}-1\right)}
$$

where $d$ is the difference between the ranks of $x_{1, i}$ and $y_{i}$ and $n$ is the number of samples.

The Spearman coefficient is similar to the Pearson coefficient with respect to calculation effort and evaluation range and adds the possibility to detect nonlinear, monotonic relationships of two variables [17].

\subsection{Measures based on statistical tests}

Correlation and regression based measures fail for nonmonotonic relationships. However, these are to be expected for the loading of floating wind turbines, e.g. tower base loads around rated wind speed or around $0^{\circ}$ wind-wave-misalignment. For identification of non-monotonic patterns, an analysis of the scatterplot of independent and dependent variables may be performed using gridding/binning and performing statistical tests to determine if the distribution across the bins is nonrandom, i.e. the bin-medians are significantly different from what would be expected for random data (called the common median or CMD approach in [27]). The procedure implemented in this work is as follows:

1. Determine the median of the sample results $y_{0.5}$

2. Divide the $x_{i}$ domain into a number of bins and assort correlated $y$-values to them such that there is a total number of $m$ bins. Let $I_{c}$ be the assorted $y$-values in the $c$-th bin.

3. Subdivide the $I_{c}$ further into values that are greater or smaller than $y_{0.5}$. Let $I_{1 c}$ be the values greater than $y_{0.5}$ and $I_{2 c}$ be values smaller than $y_{0.5}$.

4. Setup a contingency table and calculate the following statistic

$$
T=\sum_{c=1}^{m I} \sum_{r=1}^{2} \frac{\left(I_{r c}-E_{r c}\right)^{2}}{E_{r c}}
$$

where $E_{r c}$ is the expected value for the data in the $r c$ sub-bin with actual data $I_{r c}$ :

$$
E_{r c}=\frac{\sum_{p=1}^{2} I_{p c} \sum_{q=1}^{m I} I_{r q}}{n}
$$

with $n$ as the number of samples.

5. $T$ should follow a $\chi^{2}$-distribution with $m-1$ degrees of freedom, if the $I_{c}$ have equal medians. Thus, the probability of obtaining a value $T>\tilde{T}$ (with equal medians) may be calculated and used as a measure of dependency or sensitivity:

$$
p=\operatorname{prob}_{\chi^{2}}(T>\tilde{T} \mid m-1) .
$$

Smaller values for $p$ indicate a higher likelihood that the bin medians are different and hence a dependency is present.

The calculation of $p$ is quite fast. However, $p$ depends strongly on the number of available samples $n$ and does not have clear limits as the correlation measures. Hence, it is only useful if an importance ranking on a number of input variables is to be performed. Experience has shown that $S_{\chi^{2}}=|\log (p)|$ is a more intuitive indicator of importance, with larger values of $S_{\chi^{2}, i}$ indicating increased sensitivity of $y$ towards $x_{i}$.

\subsection{Sobol' Sensitivity Indices (SSI)}

The final class of sensitivity measures investigated in this paper are the variance based measures represented by the Sobol' sensitivity indices. These measures build on the decomposition of the variance of the output function into contributions from single parameters effects. Based on this, so-called Sobol' indices may be derived for first- or higher order relationships. The Firstorder indices indicate the fractional contribution of a single parameter to the output variance and are called main effects. Additionally, Total- order indices can take into account both first- and higher-order effects (sum of all indices related to a given parameter) on the output variance. The advantage of the variance based measures is that they are able to give the relative importance of an independent input parameter on the output 
function (i.e. the sum of all Sobol' indices is 1). An additional advantage over the previously mentioned measures is that the interaction effects of input parameters may be calculated.

\subsubsection{Calculation}

The derivation of the sensitivity indices is done as follows. Assume the normalized input values $\boldsymbol{x}=\left(x_{1}, x_{2}, \ldots, x_{s}\right)$ in an sdimensional independent variable space, as well as the normalized output function: $f(\boldsymbol{x}) . f(\boldsymbol{x})$ may be considered a random variable with mean $f_{0}$ and variance $D$ :

$$
\begin{gathered}
f_{0}=\int f(\boldsymbol{x}) d \boldsymbol{x} \\
D=\int f(\boldsymbol{x})^{2} d \boldsymbol{x}-f_{0}^{2}
\end{gathered}
$$

As the goal is decomposition of the output variance, the output function needs to be decomposed into an s-dimensional factor space with summands of increasing dimensionality [28]:

$$
\begin{aligned}
& f(\boldsymbol{x})=f_{0}+\sum_{i=1}^{s} f_{i}\left(x_{i}\right) \\
& +\sum_{\substack{i=1 \\
\sum_{i \neq j}}}^{s} f_{i j}\left(x_{i}, x_{j}\right) \\
& +\cdots f_{12 \ldots s}\left(x_{1}, x_{2} \ldots, x_{s}\right) .
\end{aligned}
$$

The terms of the decomposition $f_{i}\left(x_{i}\right)$ and $f_{i j}\left(x_{i}, x_{j}\right)$ are calculated through integration over all variables except the ones under consideration:

$$
\begin{gathered}
f_{i}\left(x_{i}\right)=\int f(\boldsymbol{x}) \prod_{k \neq i} d x_{k}-f_{0}, \\
f_{i j}\left(x_{i}, x_{j}\right)=\int f(x) \prod_{k \neq i, j} d x_{k}-f_{0}-f_{i}\left(x_{i}\right)-f_{j}\left(x_{j}\right) .
\end{gathered}
$$

Higher order terms are calculated accordingly. The decomposition of $f(x)$ in Equation 8 requires that "the integrals of every summand over any of its own variables must be zero" [16]:

$$
\int f_{i 1, \ldots, i s}\left(x_{i 1}, \ldots, x_{i s}\right) d x_{k}=0 \text { for } k=i_{1}, \ldots, i_{s}
$$

Because of this property, squaring both sides of Equation 8 and integrating leads to obtaining a definition of the decomposed output variance:

$$
D=\sum_{i=1}^{k} D_{i}+\sum_{i<j} D_{i j}+\sum_{i<j<l} D_{i j l}+\cdots+D_{1,2, \ldots, k}
$$

With $D_{i_{1} \ldots i_{S}}=\int f_{i_{1} \ldots i_{S}}\left(x_{i_{1}}, \ldots x_{i_{S}}\right) d x_{i_{1}}, \ldots, x_{i_{S}}$ as the variance of $f_{i_{1} \ldots i_{s}}\left(x_{i_{1}}, \ldots, x_{i_{s}}\right) . D_{i_{1} \ldots i_{s}}$ is the partial variance corresponding to a given subset of parameters.

Now the Sobol sensitivitiy indices are defined as

$$
S_{i_{1} \ldots i_{s}}=\frac{D_{i_{1} \ldots i_{s}}}{D}
$$

The first-order contribution from $i_{t h}$ input parameter to the output variance is then given by the first order indices:

$$
S_{i}=\frac{D_{i}}{D}
$$

A second-order contribution from interaction between $i_{t h}$ and $j_{t h}$ parameter is given by:

$$
S_{i j}=\frac{D_{i j}}{D}
$$

The $S_{i}$ are the partial variances, so their sum is equal to 1 :

$$
1=\sum_{i=1}^{k} S_{i}+\sum_{i<j} S_{i j}+\sum_{i<j<l} S_{i j l}+\cdots+S_{1,2, \ldots, k}
$$

The total sensitivity index of the $i_{t h}$ parameter is defined as the sum of all sensitivity indices related to it. It quantifies the overall effect of one parameter on the model output:

$$
S_{T i}=S_{i}+S_{i j_{i \neq j}}+\cdots+S_{1 \ldots i \ldots s}
$$

The values for the indices range between 0 and 1 . The sum of the first order indices will be smaller than 1 and the sum of the total indices will always be larger than 1 . Also, the total indices are typically larger than the first-order indices. As a threshold value for relevant input parameters, 0.05 is typically accepted [29].

\subsubsection{Implementation}

From a numerical perspective, the main challenge for the calculation of the Sobol indices is the evaluation of the integrals given in Eq. 9 and 10. This may be done via Monte Carlo simulations, as an integral may be solved numerically according to

$$
\int_{[0,1]^{S}} f(x) d x \approx \frac{1}{N} \sum_{i=1}^{N} f\left(\xi_{i}\right),
$$

where $\xi_{i} \epsilon[0,1]^{s}$ are each of $N$ random, independent samples in the $s$-dimensional unit hypercube. Different strategies exist for the selection of the $N$ random points, such as purely random or crude, stratified (e.g. via latin hypercube sampling) or quasirandom (e.g. via Sobol' sequences). These strategies show different performances with respect to convergence speed. A combination of the random points used for the evaluation in order to be able to calculate Sobol' indices efficiently is presented in [30] [31]. Overall, the calculation of Sobol' sensitivity indices requires the evaluation over the full range of the parameter space and many functional evaluations are necessary in order to achieve converged results. The adequate sample size depends on the number of parameters and is given by uncertainty of predicted sensitivity, which can be obtained from bootstrap analysis. For the most relevant parameters a narrow confidence intervals should be achieved (i.e. $<10 \%$ of sensitivity index) [5]. As a rule of thumb, about 100,000 model 
evaluations for a large number of independent parameters $(>20)$ and 1,000 model evaluations for less complex models can be expected. As this is often too expensive from a computational point of view, surrogate models may be evaluated instead. While surrogate models may be obtained from a limited set of simulations, they also introduce a new uncertainty to the determined sensitivity measures resulting from the added modeling step, which may limit the quality of the results. Possible alternatives for surrogate models are polynomial functions, neural networks, support vector machines, kriging, or polynomial chaos expansion [9], which may be particular interesting as the calculation of Sobol' indices is done implicitly. In this work, an attempt is made to use arbitrary one-layer feedforward neural networks with 1 hidden layer with 50 neurons. Of all available input-output samples, $70 \%$ are used for training, $15 \%$ for testing and $15 \%$ for validation. For the training, the Levenberg-Marquardt algorithm was used [32]. A less computationally costly alternative to Sobol' indices may be the Fourier amplitude sensitivity test. There, each parameter is assigned with a characteristic frequency. The variance contribution of a specific parameter is then determined via the model output for a given set of simulation results and this characteristic frequency [19].

\section{REFERENCE STUDY}

In parallel to the work done with the NAUTILUS-10 floating platform, the LIFES50+ project also studied the public model of the 10MW semi-submersible platform of the OO Start wind Floater [33]. The results from different simulation studies as well as sensitivity studies are presented in [34] and a more complete report is planned within the Deliverable 7.7 from the LIFES50+ project. Nevertheless, for the mentioned publication, the sensitivity study shown involves the analysis of the DELs for DLC 1.2. Here, three parameters are varied: wind speed, wave height and wave period. Also three load ranges are defined for differentiating between fundamentally different system behaviors based on the controller mode: partial load range (LR) below rated wind speed (LR1), transitional load range around rated wind speed (LR2) and full load range above rated wind speed (LR3). A total of 2799 simulations of 3600s were ran and for three sensor positions a DEL was calculated. These sensors are the blade root bending moment, tower bottom fore-aft bending moment, and fairlead tension, which are calculated as a function of the wind direction. The chi-square test (as described in section 3.2) is performed for each environmental parameter and LR. The chi-square test results in a p-value which gives the probability that the correlation between two observed variables is random.

The results of the study show that the blade root bending moment DELs correlate best with the wind speed, while the fairlead tension correlates best with the wave height. In the case of the tower base fore-aft DEL, depending on the load case, different environmental conditions seem to be more important. For the region around rated and above, it is the wave height that shows the best correlation, while below rated it is the wind speed.

\section{RESULTS AND DISCUSSION}

This chapter provides an overview of the results obtained from the different load cases. Essentially, the evaluation is built upon scatter plots to show first-order relationships and contour plots to show second-order relationships. Plotting higher-order relationships than second order is regarded as infeasible due to the large number of plots as well as the high dimensionality of the plots (i.e. 4 dimensions for third-order relationships). Next to the scatterplots, some plots are provided to show the methodology of training the neural network as well as the results of the sensitivity analysis.

\subsection{DLC 1.2}

Fatigue loads during power production are investigated in DLC1.2. Damage equivalent loads (DEL) with reference cycle number of $N_{\text {ref }}=2 \cdot 10^{6}$ are calculated from the simulated time series. Of the three calculated seeds for each combination of environmental variables, the mean DEL was used for evaluation. TABLE 1 gives an overview of the settings of environmental conditions used for DLC 1.2 simulations.

\begin{tabular}{|c|c|c|c|}
\hline \multicolumn{4}{|c|}{ Simulation Settings } \\
\hline \multicolumn{2}{|c|}{ Environmental conditions } & $\begin{array}{c}\text { Number of } \\
\text { simulations [-] }\end{array}$ & $\begin{array}{c}\text { Simulation time } \\
\text { [s] }\end{array}$ \\
\hline Wind speed $[\mathrm{m} / \mathrm{s}]$ & $\begin{array}{l}\text { LR1: } 4.0: 0.1: 10.2 \\
\text { LR2: } 10.2: 0.1: 13.8 \\
\text { LR3: } 13.8: 0.1: 25.0\end{array}$ & \multirow{8}{*}{10368} & \multirow{8}{*}{$4600(3600)$} \\
\hline Turbulence Intensity [-] & Class C & & \\
\hline Wind direction $\left[^{\circ}\right]$ & $0: 15: 345$ & & \\
\hline Wind seeds [-] & 3 & & \\
\hline Wave height [m] & $\begin{array}{l}\text { LR1:0.3:0.1:3.1 } \\
\text { LR2: } 0.3: 0.1: 4.0 \\
\text { LR3: } 1.2: 0.1: 6.6\end{array}$ & & \\
\hline Wave period [s] & $\begin{array}{l}\text { LR1:2.5: } 0.1: 10.7 \\
\text { LR2: } 2.5: 0.1: 10.7 \\
\text { LR3: } 4.0: 0.1: 10.7\end{array}$ & & \\
\hline Wave direction $\left[{ }^{\circ}\right]$ & $0: 15: 345$ & & \\
\hline Wave seeds [-] & 3 & & \\
\hline
\end{tabular}

FIGURE 2 shows an exemplary scatterplot of DLC1.2 results for the tower base resulting bending moment. The large impact of wind speed in all load ranges is visible. Also, the DEL increases significantly with wind speed at wind speeds below rated. A more complex relationship between DEL and wind speed is visible around and in particular above rated. The wave height becomes more relevant with larger wave heights (this trend starts at around three meter wave height). Regarding the wave periods, larger DELs are more likely around 8s. This effect is more distinctive for larger wind speeds / wave heights. A similar behavior was also documented for the Olav Olsen platform [34]. Thus, this effect may be related to the rated rotor speed, which has a period of around 7s for the DTU 10MW reference wind turbine and could lead to a similar effect on both structures. 

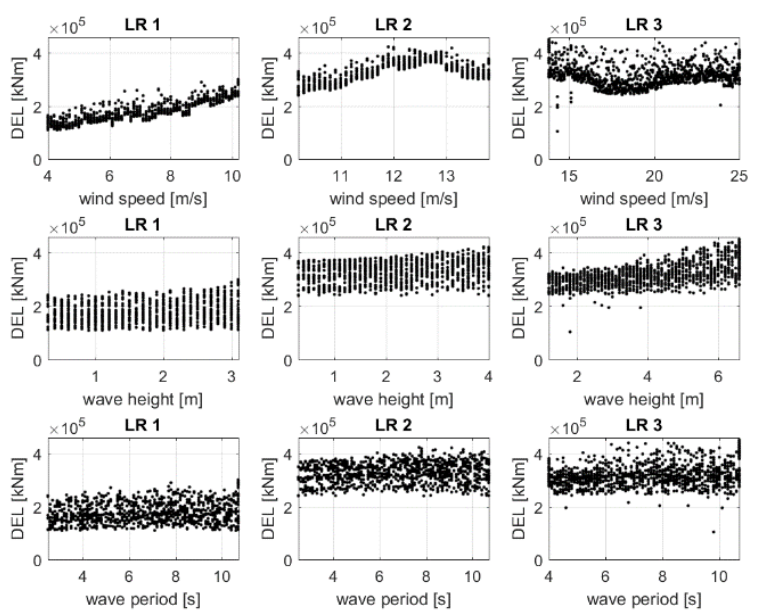

FIGURE 2: DLC1.2 DEL RESULTS OF SIMULATION STUDY FOR TOWER BASE RESULTING BENDING MOMENT. COLUMNS INDICATING DIFFERENT LOAD RANGES (LR) BASED ON WIND SPEEDS, ROWS INDICATING DIFFERENT ENVIRONMENTAL CONDITIONS.

FIGURE 3 summarizes an exemplary training procedure of the neural network surrogate model which is used for the determination of the Sobol' sensitivity indices. The scatter plot, regression plot and the error histograms give qualitative information of the performance of the surrogate model. The shown surrogate is able to reproduce the first order dependencies and overall regression is satisfactory (correlation $R>0.9$ ). A significant amount of errors is above $10 \%$, which may influence the quality of the results. However, the errors roughly follow a normal distribution (i.e. overestimation equally likely as underestimation), which indicates that errors may be reduced through repeated evaluations (bootstrapping). The final plot gives a summary on the training procedure. The performance measure for the regression is the mean squared error, which needs to be reduced by adjusting the weights and biases of the neurons. Typically the error increases, once overfitting on the training data occurs, which is why the training is terminated as soon as the performance measure evaluated on the validation and test sets reaches a minimum.
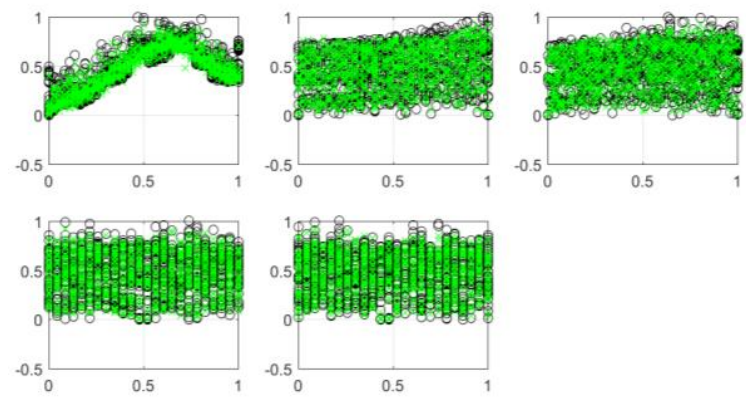

(a)

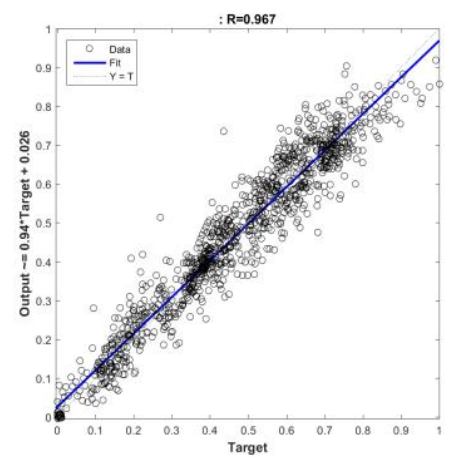

(b)

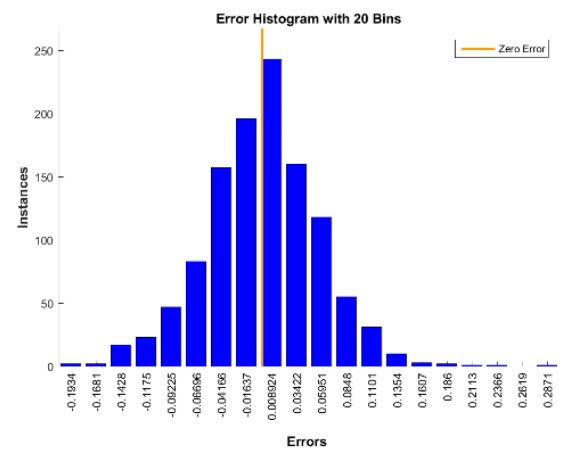

(c)

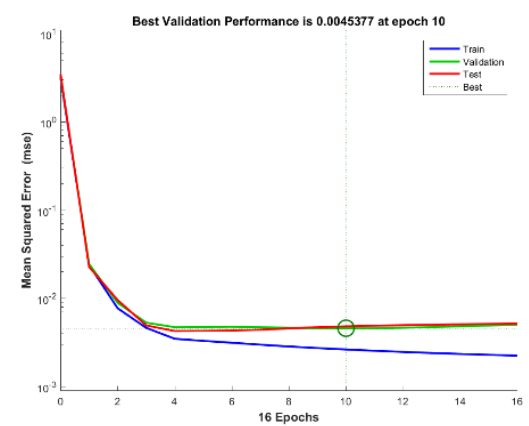

(d)

FIGURE 3: DLC1.2 NEURAL NETWORK SURROGATE MODEL EVALUATION FOR TOWER BASE RESULTING BENDING MOMENT IN LOAD RANGE 2. (A) SCATTERPLOT OF SIMULATION RESULTS (BLACK) WITH RESULTS FROM NEURAL NETWORK SURROGATE MODEL (GREEN) FOR 5 INDEPENDENT VARIABLES, (B) REGRESSION PLOT OVER ALL PREDICTED LOADS, (C) ERROR HISTOGRAM OF NEURAL NETWORK SURROGATE MODEL, (D) SUMMARY OF NETWORK TRAINING

Based on the available results and the surrogate model, the sensitivity measures described in section 3 where calculated. FIGURE 4 shows the Sobol' first and total order indices. From the first order indices (direct impact), a large influence of wind speed is documented, as well as some impact of the wind direction. The total order indices (direct and mixed impact) show also a relevant impact of wave height and wave period (not visible in scatter plots) as well as wind and wave direction (visible in scatterplots through wind-wave misalignment). The 
resulting importance from the Sobol' indices for wave height and wave period cannot be seen in neither the scatterplots nor the combined contour plots. Because it is not possible to verify the higher-order interactions by visual means, it is strongly recommended to use a sufficiently large number of evaluations from different neural networks as well as performing a convergence study of the calculation of the Sobol' indices (with increasing surrogate model evaluations). Only this way it can be ensured that the uncertainties of the sensitivity analysis approach are taken into account appropriately and not built into the evaluation.

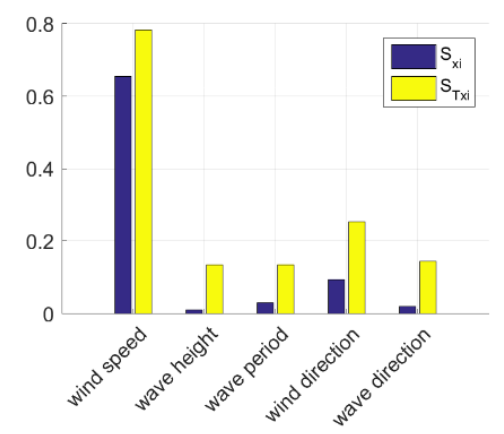

FIGURE 4: DLC1.2 SOBOL' SENSITIVITY INDICES FOR MAXIMUM DEL OF ALL FAIRLEAD TENSIONS, LOAD RANGE 2 (AROUND RATED WIND SPEED).

TABLE 2 Shows the results of the considered sensitivity indices for the main system components over the three evaluated load ranges. It can be seen that, as expected, the Pearson and Spearman coefficients perform poorly as soon as the dependency is not strictly monotonic (e.g. wind speed around rated). If the wind-wave-misalignment is calculated and used in the evaluation, which is possible for coefficients that focus on first order dependency (Pearson, Spearman and chisquare), the chisquare method is able to detect this periodic dependency. The Sobol' method detects this relationship via the total indices, although from the results it is not directly clear that the combination of the directionality will be the reason for this increased importance. The impact of the wave period for tower base loading may be underestimated by the chisquare method. For the NAUTILUS-DTU10 FOWT the loads on the rotor blades are only influenced by the wind speed, which is documented by all sensitivity measures. For the tower base loading, the influence of wave height and wave period may be underestimated by the chisquare and Sobol' first order indices. For the Sobol' indices, a value above 0.05 is considered important. Note, however that no repetition in the calculation of the index is performed in this study, which is why the reported measures may vary due to statistical variation. Some interaction effect of wave height and period is reported from the Sobol' indices for LR2 of the fairlead tensions, which is not detected by the other indices, and can also not be seen in the two-way correlation plots (contour plots, see FIGURE 6). This type of interaction may be of interest in a further study, especially regarding the means of verification, which is not possible with the tools available in this study.

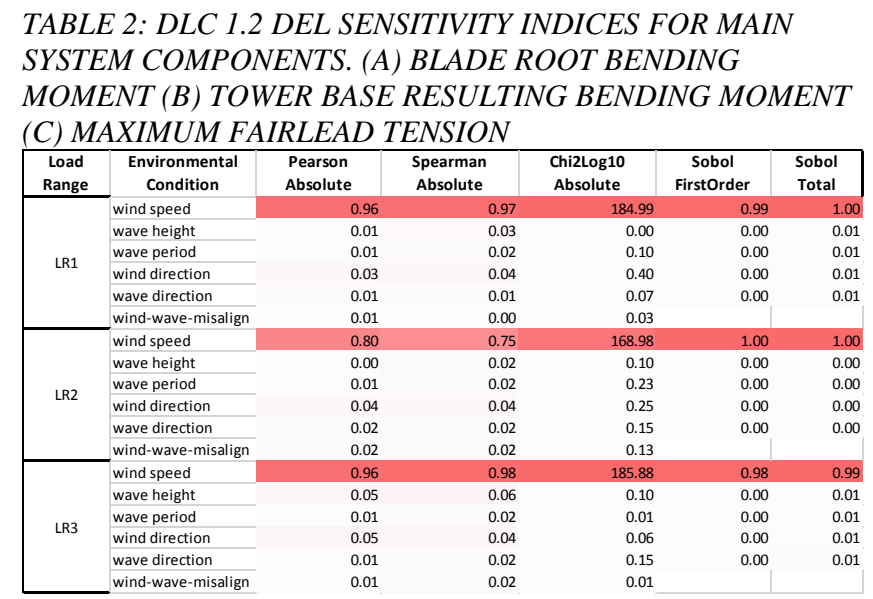

(a)

\begin{tabular}{|c|lrrrrr|}
\hline $\begin{array}{c}\text { Load } \\
\text { Range }\end{array}$ & $\begin{array}{c}\text { Environmental } \\
\text { Condition }\end{array}$ & $\begin{array}{c}\text { Pearson } \\
\text { Absolute }\end{array}$ & $\begin{array}{c}\text { Spearman } \\
\text { Absolute }\end{array}$ & $\begin{array}{c}\text { Chi2Log10 } \\
\text { Absolute }\end{array}$ & $\begin{array}{c}\text { Sobol } \\
\text { Firstorder }\end{array}$ & $\begin{array}{c}\text { Sobol } \\
\text { Total }\end{array}$ \\
\hline \multirow{5}{*}{ wind speed } & 0.89 & 0.90 & 134.69 & 0.83 & 0.85 \\
& wave height & 0.19 & 0.17 & 4.30 & 0.10 & 0.12 \\
& wave period & 0.15 & 0.13 & 2.35 & 0.02 & 0.04 \\
& wind direction & 0.04 & 0.05 & 1.03 & 0.01 & 0.02 \\
& wave direction & 0.01 & 0.01 & 0.10 & 0.00 & 0.02 \\
& wind-wave-misalign & 0.02 & 0.02 & 1.78 & & \\
\hline \multirow{5}{*}{ LR2 } & wind speed & 0.61 & 0.57 & 143.45 & 0.86 & 0.88 \\
& wave height & 0.23 & 0.22 & 12.48 & 0.05 & 0.09 \\
& wave period & 0.18 & 0.18 & 9.52 & 0.02 & 0.07 \\
& wind direction & 0.02 & 0.02 & 5.55 & 0.00 & 0.03 \\
& wave direction & 0.02 & 0.02 & 3.06 & -0.01 & 0.02 \\
& wind-wave-misalign & 0.00 & 0.01 & 1.63 & & \\
\hline \multirow{5}{*}{ LR3 } & wind speed & 0.01 & 0.01 & 34.50 & 0.17 & 0.34 \\
& wave height & 0.55 & 0.53 & 36.61 & 0.30 & 0.47 \\
& wave period & 0.21 & 0.19 & 4.95 & 0.07 & 0.24 \\
& wind direction & 0.02 & 0.05 & 7.44 & 0.04 & 0.31 \\
& wave direction & 0.02 & 0.02 & 2.29 & 0.01 & 0.27 \\
& wind-wave-misalign & 0.02 & 0.00 & 13.45 & & \\
\hline
\end{tabular}

(b)

\begin{tabular}{|cllrrrrrr|}
\hline \multirow{2}{*}{$\begin{array}{c}\text { Load } \\
\text { Range }\end{array}$} & \multicolumn{1}{c}{$\begin{array}{c}\text { Environmental } \\
\text { Condition }\end{array}$} & $\begin{array}{c}\text { Pearson } \\
\text { Absolute }\end{array}$ & $\begin{array}{c}\text { Spearman } \\
\text { Absolute }\end{array}$ & $\begin{array}{c}\text { Chi2Log10 } \\
\text { Absolute }\end{array}$ & $\begin{array}{c}\text { Sobol } \\
\text { AirstOrder }\end{array}$ & $\begin{array}{c}\text { Sobol } \\
\text { Total }\end{array}$ \\
\hline \multirow{3}{*}{ LR1 } & wind speed & 0.94 & 0.96 & 183.26 & 0.97 & 0.99 \\
& wave height & 0.02 & 0.02 & 0.19 & 0.00 & 0.01 \\
& wave period & 0.02 & 0.02 & 0.28 & 0.00 & 0.01 \\
& wind direction & 0.01 & 0.01 & 0.40 & 0.00 & 0.01 \\
& wave direction & 0.00 & 0.00 & 0.06 & 0.00 & 0.01 \\
& wind-wave-misalign & 0.01 & 0.01 & 0.05 & & \\
\hline \multirow{5}{*}{ LR2 } & wind speed & 0.03 & 0.04 & 46.63 & 0.65 & 0.78 \\
& wave height & 0.04 & 0.04 & 4.98 & 0.01 & 0.13 \\
& wave period & 0.03 & 0.03 & 2.66 & 0.03 & 0.13 \\
& wind direction & 0.09 & 0.08 & 35.57 & 0.09 & 0.25 \\
& wave direction & 0.01 & 0.01 & 11.77 & 0.02 & 0.14 \\
& wind-wave-misalign & 0.01 & 0.03 & 3.95 & & \\
\hline \multirow{5}{*}{ LR3 } & wind speed & 0.65 & 0.70 & 94.25 & 0.64 & 0.67 \\
& wave height & 0.32 & 0.36 & 22.90 & 0.12 & 0.19 \\
& wave period & 0.28 & 0.28 & 12.06 & 0.11 & 0.19 \\
& wind direction & 0.06 & 0.07 & 0.17 & 0.00 & 0.04 \\
& wave direction & 0.01 & 0.00 & 0.59 & 0.00 & 0.05 \\
& wind-wave-misalign & 0.02 & 0.01 & 3.61 & & \\
\hline
\end{tabular}

(c)

\subsection{DLC 1.6}

Ultimate loads during power production during a severe sea state are investigated in DLC 1.6. From the simulated time series, maximum values are calculated. Three seeds for each combination of environmental parameters are available and the mean of the max of the seeds was calculated and is considered in the sensitivity analysis. TABLE 3 gives an overview of the 
settings of environmental conditions used for DLC 1.6 simulations.

TABLE 3: SIMULATION SETTINGS FOR DLC 1.6

\begin{tabular}{|c|c|c|c|}
\hline \multicolumn{4}{|c|}{ Simulation Settings } \\
\hline \multicolumn{2}{|c|}{ Environmental conditions } & $\begin{array}{c}\text { Number of } \\
\text { simulations [-] }\end{array}$ & $\begin{array}{c}\text { Simulation time } \\
{[\mathbf{s}]}\end{array}$ \\
\hline Wind speed $[\mathrm{m} / \mathrm{s}]$ & $\begin{array}{l}\text { LR1: } 4.0: 0.1: 10.2 \\
\text { LR2: } 10.2: 0.1: 13.8 \\
\text { LR3: } 13.8: 0.1: 25.0\end{array}$ & \multirow{9}{*}{11520} & \multirow{9}{*}{$11800(10800)$} \\
\hline Turbulence Intensity [-] & Class $\mathrm{C}$ & & \\
\hline Wind direction $\left[{ }^{\circ}\right]$ & $0: 15: 345$ & & \\
\hline Wind seeds $[-]$ & 3 & & \\
\hline Wave height $[\mathrm{m}]$ & $10.4: 0.1: 11.4$ & & \\
\hline Wave period $[s]$ & $7.2: 0.1: 20$ & & \\
\hline Wave direction $\left[{ }^{\circ}\right]$ & $0: 15: 345$ & & \\
\hline Wave seeds $[-]$ & 3 & & \\
\hline Water depth $[\mathrm{m}]$ & $-134.3: 0.1:-129.2$ & & \\
\hline
\end{tabular}

Exemplary for the maximum fairlead tension, FIGURE 5 shows the large impact of wind speed in the first and the third load range (LR1 and LR3). Maximum loads increase significantly with wind speed at wind speeds below rated and decline with increasing wind speed above rated. No significant impact of wave height is visible, which may be linked to the small range investigated (+/- $10 \%$ of $50 \mathrm{yr}$ wave height). This indicates that even large errors in the design assumptions will not lead to large errors in the predicted load. Contrary to the fatigue loads, the wave period has a large effect on the maximum loads in the way that very small wave periods (all load ranges) as well as large periods (first and second load range) lead to increased maximum loads. Wind-wave-misalignment also seems to be important with a misalignment of $0^{\circ}$ leading to the highest loads. For load range two, a misalignment of $180^{\circ}$ may also lead to high loading. The sensitivity is quite strong on wind-wave misalignment and wave periods, which indicates that a probabilistic approach taking into account the probability of occurrence of the environmental parameters may lead to less conservative design (then, not only the scenario leading to the highest load is to be considered).
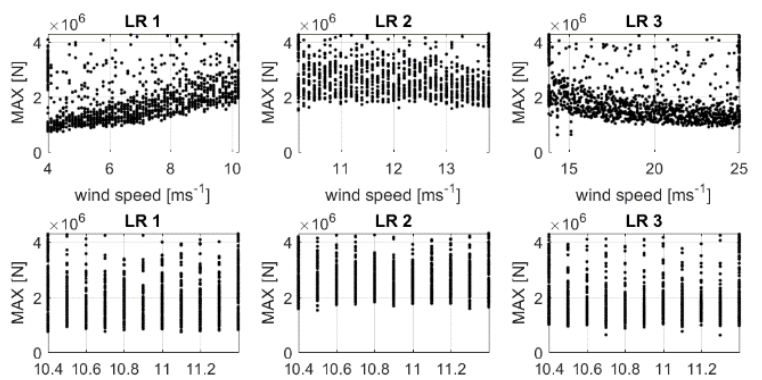

wind speed $[\mathrm{ms}$

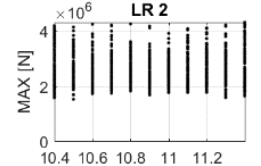

z

$x^{6} \quad$ LR

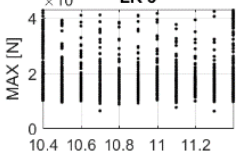

wave height $[\mathrm{m}]$
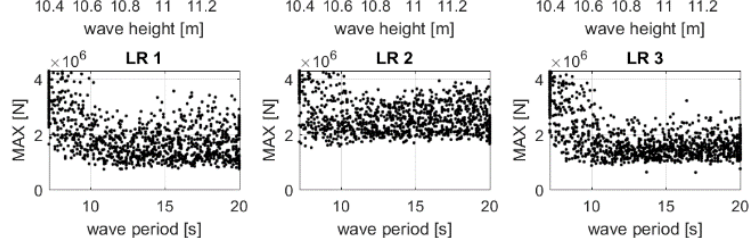
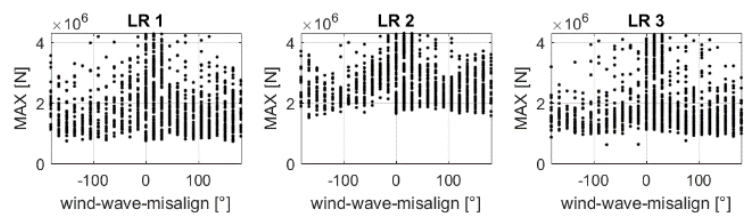

FIGURE 5: DLC1.6 MAX LOAD RESULTS OF SIMULATION STUDY FOR FAIRLEAD TENSIONS. COLUMNS INDICATING DIFFERENT LOAD RANGES (LR), ROWS INDICATING DIFFERENT ENVIRONMENTAL CONDITIONS.

FIGURE 6 shows the two-way interaction effects of different environmental conditions on the maximum loads of the fairlead tension in the first load range below rated wind speed (same data points used as for FIGURE 5, first column). The contours indicate the normalized maximum loading on any of the four fairleads. The red dots indicate the combinations that were simulated. If more than one simulation was performed for an indicated combination of environmental parameters, the contour shows the mean (interpolated) value. As exemplary evaluation the interaction between wave period and wind speed is of interest: It is visible how the impact of small wave periods diminishes with increasing wind speed, and even how large wave periods only have an increased relevance for large wind speeds.

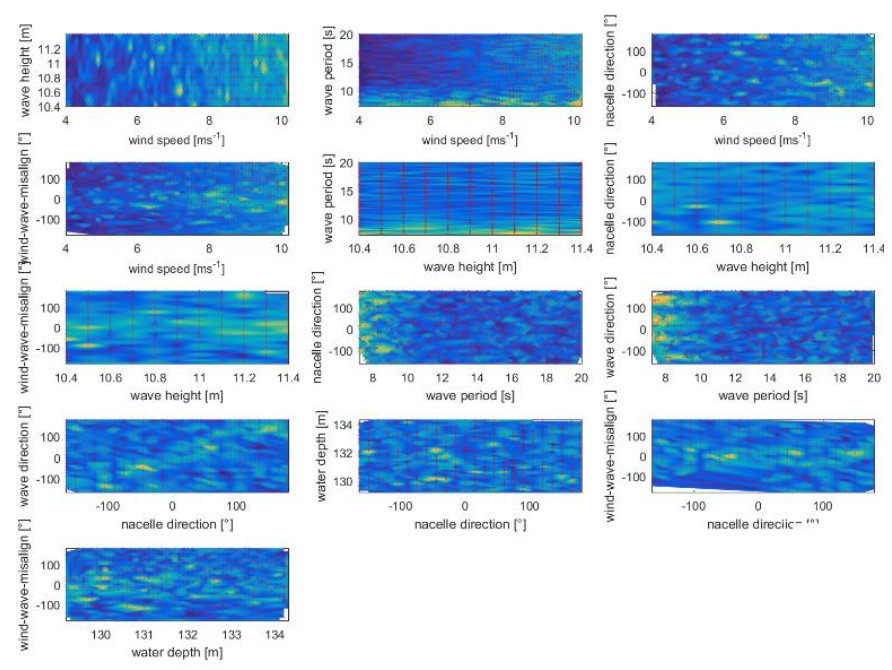




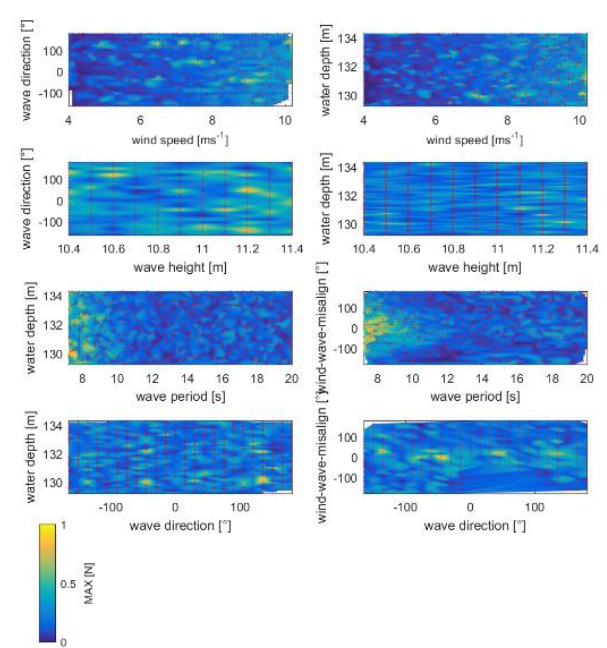

FIGURE 6: DLC 1.6 TWO-WAY INTERACTION CONTOUR PLOTS FOR FAIRLEAD TENSION MAXIMUM LOADS IN LOAD RANGE 1. NORMALIZED MAXIMUM LOADS ARE SHOWN. RED DOTS INDICATE THE PERFORMED SIMULATIONS.

TABLE 4 shows the results of the considered sensitivity indices for the main system components over the three evaluated load ranges. Again for the maximum loads of the blade root bending moment, largely only the wind speed is detected to have a significant impact. However, some impact is also detected for the wave periods (which is increased, when interaction effects are taken into account) as well as a minor impact of wind-wave misalignment which is only detected through the Sobol' total index (load range two and three) and the chisquare measure (load range 3 ). A small impact is also detected for the water depth from the Sobol' total indices.

For the tower base resulting bending moment, the relevant loads are wind speed (all load ranges), wave period (all load ranges) and wind-wave misalignment (third load range). Some minor impact of the wave height through interaction effects is also detected by the Sobol' total index for the second and third load ranges. The impact of the wind speed appears to be overrated by the Pearson and Spearman measures for the first load range and underrated by the chi-square measure for the second load range. A small impact is also detected for the water depth from the Sobol' total indices.

For the fairlead tension, wind speed (all load ranges), wave period (all load ranges), wind-wave-misalignment (all load ranges) and wave height (minor importance with different magnitude detected for all load ranges) are of importance. A quite large impact of water depth is detected from the Sobol' analysis. This cannot be confirmed by the second-order interaction plots. This again may indicate some uncertainty in the prediction of the Sobol' indices and underlines the importance of convergence analysis for this method in order to have sufficient trust in the measure.
TABLE 4: DLC 1.6 MAX LOAD SENSITIVITY INDICES FOR MAIN SYSTEM COMPONENTS. (A) BLADE ROOT BENDING MOMENT (B) TOWER BASE RESULTING BENDING MOMENT (C) MAXIMUM FAIRLEAD TENSION

\begin{tabular}{|c|c|c|c|c|c|c|}
\hline $\begin{array}{l}\text { Load } \\
\text { Range }\end{array}$ & $\begin{array}{l}\text { Environmental } \\
\text { Condition }\end{array}$ & $\begin{array}{l}\text { Pearson } \\
\text { Absolute }\end{array}$ & $\begin{array}{c}\text { Spearman } \\
\text { Absolute }\end{array}$ & $\begin{array}{l}\text { Chi2Log10 } \\
\text { Absolute }\end{array}$ & $\begin{array}{c}\text { Sobol } \\
\text { FirstOrder }\end{array}$ & $\begin{array}{l}\text { Sobol } \\
\text { Total }\end{array}$ \\
\hline \multirow{7}{*}{ LR1 } & wind speed & 0.98 & 0.98 & 197.74 & 0.99 & 1.00 \\
\hline & wave height & 0.03 & 0.03 & 0.24 & 0.00 & 0.00 \\
\hline & wave period & 0.06 & 0.09 & 0.34 & 0.00 & 0.01 \\
\hline & wind direction & 0.01 & 0.02 & 0.01 & 0.00 & 0.00 \\
\hline & wave direction & 0.01 & 0.01 & 0.16 & 0.00 & 0.00 \\
\hline & water depth & 0.01 & 0.01 & 0.03 & 0.00 & 0.00 \\
\hline & wind-wave-misalign & 0.01 & 0.01 & 0.08 & & \\
\hline \multirow{7}{*}{ LR2 } & wind speed & 0.39 & 0.38 & 106.38 & 0.75 & 0.84 \\
\hline & wave height & 0.03 & 0.04 & 7.58 & 0.00 & 0.09 \\
\hline & wave period & 0.31 & 0.29 & 4.64 & 0.11 & 0.18 \\
\hline & wind direction & 0.01 & 0.02 & 11.08 & 0.00 & 0.06 \\
\hline & wave direction & 0.02 & 0.01 & 11.57 & 0.00 & 0.06 \\
\hline & water depth & 0.04 & 0.03 & 2.55 & -0.01 & 0.04 \\
\hline & wind-wave-misalign & 0.01 & 0.02 & 7.81 & & \\
\hline \multirow{7}{*}{ LR3 } & wind speed & 0.67 & 0.64 & 93.92 & 0.75 & 0.85 \\
\hline & wave height & 0.02 & 0.04 & 0.76 & 0.00 & 0.05 \\
\hline & wave period & 0.22 & 0.33 & 39.20 & 0.12 & 0.19 \\
\hline & wind direction & 0.01 & 0.03 & 3.52 & 0.01 & 0.06 \\
\hline & wave direction & 0.02 & 0.01 & 2.91 & 0.00 & 0.06 \\
\hline & water depth & 0.00 & 0.02 & 1.82 & 0.01 & 0.06 \\
\hline & wind-wave-misalign & 0.02 & 0.05 & 20.58 & & \\
\hline
\end{tabular}

(a)

\begin{tabular}{|c|c|c|c|c|c|c|}
\hline $\begin{array}{l}\text { Load } \\
\text { Range }\end{array}$ & $\begin{array}{l}\text { Environmental } \\
\text { Condition }\end{array}$ & $\begin{array}{l}\text { Pearson } \\
\text { Absolute }\end{array}$ & $\begin{array}{l}\text { Spearman } \\
\text { Absolute }\end{array}$ & $\begin{array}{l}\text { Chi2Log10 } \\
\text { Absolute }\end{array}$ & $\begin{array}{c}\text { Sobol } \\
\text { FirstOrder }\end{array}$ & $\begin{array}{l}\text { Sobol } \\
\text { Total }\end{array}$ \\
\hline \multirow{7}{*}{ LR1 } & wind speed & 0.55 & 0.53 & 31.64 & 0.30 & 0.33 \\
\hline & wave height & 0.11 & 0.10 & 5.50 & 0.00 & 0.02 \\
\hline & wave period & 0.73 & 0.72 & 122.11 & 0.60 & 0.63 \\
\hline & wind direction & 0.04 & 0.03 & 4.32 & 0.00 & 0.06 \\
\hline & wave direction & 0.00 & 0.01 & 5.54 & 0.00 & 0.06 \\
\hline & water depth & 0.02 & 0.03 & 3.97 & 0.00 & 0.02 \\
\hline & wind-wave-misalign & 0.04 & 0.04 & 13.68 & & \\
\hline \multirow{7}{*}{ LR2 } & wind speed & 0.21 & 0.23 & 14.73 & 0.12 & 0.18 \\
\hline & wave height & 0.10 & 0.08 & 2.45 & 0.00 & 0.06 \\
\hline & wave period & 0.78 & 0.77 & 108.85 & 0.75 & 0.80 \\
\hline & wind direction & 0.03 & 0.03 & 0.09 & 0.00 & 0.06 \\
\hline & wave direction & 0.01 & 0.01 & 0.05 & -0.01 & 0.06 \\
\hline & water depth & 0.02 & 0.03 & 0.63 & 0.00 & 0.04 \\
\hline & wind-wave-misalign & 0.06 & 0.07 & 18.91 & & \\
\hline \multirow{7}{*}{ LR3 } & wind speed & 0.31 & 0.32 & 35.01 & 0.09 & 0.21 \\
\hline & wave height & 0.08 & 0.07 & 3.09 & 0.01 & 0.08 \\
\hline & wave period & 0.76 & 0.74 & 146.37 & 0.69 & 0.79 \\
\hline & wind direction & 0.02 & 0.03 & 6.55 & 0.01 & 0.14 \\
\hline & wave direction & 0.01 & 0.00 & 5.97 & 0.00 & 0.13 \\
\hline & water depth & 0.02 & 0.02 & 2.39 & 0.00 & 0.07 \\
\hline & wind-wave-misalign & 0.06 & 0.06 & 18.49 & & \\
\hline
\end{tabular}

(b) 


\begin{tabular}{|c|c|c|c|c|c|c|}
\hline $\begin{array}{l}\text { Load } \\
\text { Range }\end{array}$ & $\begin{array}{l}\text { Environmental } \\
\text { Condition }\end{array}$ & $\begin{array}{l}\text { Pearson } \\
\text { Absolute }\end{array}$ & $\begin{array}{c}\text { Spearman } \\
\text { Absolute }\end{array}$ & $\begin{array}{l}\text { Chi2Log10 } \\
\text { Absolute }\end{array}$ & $\begin{array}{c}\text { Sobol } \\
\text { First Order }\end{array}$ & $\begin{array}{l}\text { Sobol } \\
\text { Total }\end{array}$ \\
\hline \multirow{7}{*}{ LR1 } & wind speed & 0.47 & 0.55 & ; $\quad 59.83$ & 0.25 & 0.37 \\
\hline & wave height & 0.10 & 0.08 & 4.49 & 0.02 & 0.06 \\
\hline & wave period & 0.54 & 0.47 & 54.42 & 0.41 & 0.63 \\
\hline & wind direction & 0.02 & 0.02 & 5.11 & 0.01 & 0.26 \\
\hline & wave direction & 0.02 & 0.01 & 6.44 & 0.01 & 0.21 \\
\hline & water depth & 0.02 & 0.00 & 3.45 & 0.00 & 0.05 \\
\hline & wind-wave-misalign & 0.06 & 0.09 & 19.80 & & \\
\hline \multirow{7}{*}{ LR2 } & wind speed & 0.14 & 0.19 & 8.66 & 0.07 & 0.23 \\
\hline & wave height & 0.10 & 0.06 & 0.78 & 0.01 & 0.18 \\
\hline & wave period & 0.47 & 0.39 & 17.73 & 0.36 & 0.59 \\
\hline & wind direction & 0.02 & 0.01 & 0.16 & 0.01 & 0.37 \\
\hline & wave direction & 0.03 & 0.04 & 0.89 & 0.03 & 0.37 \\
\hline & water depth & 0.01 & 0.01 & 0.18 & 0.00 & 0.16 \\
\hline & wind-wave-misalign & 0.06 & 0.09 & 15.29 & & \\
\hline \multirow{7}{*}{ LR3 } & wind speed & 0.23 & 0.39 & 55.46 & 0.13 & 0.18 \\
\hline & wave height & 0.09 & 0.09 & 1.18 & 0.02 & 0.05 \\
\hline & wave period & 0.60 & 0.47 & 59.42 & 0.54 & 0.70 \\
\hline & wind direction & 0.01 & 0.03 & 6.53 & 0.02 & 0.27 \\
\hline & wave direction & 0.02 & 0.01 & 7.40 & 0.01 & 0.25 \\
\hline & water depth & 0.00 & 0.03 & 0.70 & 0.01 & 0.07 \\
\hline & wind-wave-misalign & 0.06 & 0.10 & 28.38 & & \\
\hline
\end{tabular}

(c)

\section{CONCLUSIONS}

This work highlighted the use, applicability of GSA for new concepts of floating wind turbine substructures. While different measures may be considered, it is advised to focus on variance based measures such as the herein applied Sobol' indices as they are the only measure able to capture more complex interaction effects.

Through the GSA it is possible to identify relevant parameters across the design space for different components. Interestingly, the observed concept showed small impact of the wave environment on the blade loading during power production, which could indicate the possibility of a reduced design effort on the RNA. The GSA approach also served as a rigorous test of the implemented model as many different environmental conditions with high resolution may be investigated. This helped to identify some open questions in the used numerical model for DLC 6.1 which remains to be investigated in future studies. Also, in case of interest, simplified first-order relationships may be derived from the obtained scatterplots for main components.

Regarding the application of GSA, the following conclusions were made:

- Correlation based measures fail for nonmonotonic relationships. These were identified for wind speed around and above rated, directionalities and wave period.

- $\quad$ Statistical test based measures (e.g. chi-square measure) worked well in this study, if wind-wave misalignment is calculated from simulation input and is considered as separate environmental variable (only first-order effects may be considered).

- For the near future, it is assumed to be best to calculate a number of fundamentally different indices in order to have a robust result and increase trust and experience with the implementations of variance based methods. As
Sobol' indices are the only measures that are expensive to calculate, this should not pose a problem in future studies.

- Calculating distinct higher order Sobol' sensitivity indices rather than only the total sensitivity index could be helpful in order to determine the exact origin of the sensitivity, as the origin of the sensitivity (i.e. the specific influential interaction effects) cannot be interpreted directly from the total index.

- Sobol' sequences perform well overall, but are sometimes hard to interpret. Then, it is not clear if the obtained sensitivity is part of the physical or the surrogate model. Hence, when using variance based approaches based on surrogate models it is advised to (a) perform a statistical analysis of the used surrogate model to determine the model uncertainties and (b) to perform a convergence study of the Sobol' indices in order to ensure that the uncertainties from the calculation procedure are adequately taken into account.

\section{ACKNOWLEDGMENTS}

The present work was carried out as part of the LIFES50+ project, which has received funding from the European Union's Horizon 2020 research and innovation program under grant agreement no. 640741. The funding and support is gratefully acknowledged.

Also, it is kindly noted that the necessary information to rebuild the numerical model used in this work is available at: www.researchgate.net/project/NAUTILUS-DTU10-MWFloating-Offshore-Wind-Turbine-at-Gulf-of-Maine

\section{REFERENCES}

[1] International Electrotechnical Commission , "Wind Turbines - Part 3: Design Requirements for Offshore Wind Turbines," 61400-03, 2009.

[2] Det Norske Veritas AS, "Design of Floating Wind Turbine Structures," DNV-OS-J103, 2013.

[3] M. Borg, M. Mirzaei and H. Bredmose, " LIFES50+ D1.2: Wind Turbine models for the design," 2015.

[4] C. Bak, "Description of the DTU 10 MW reference wind turbine," DTU Wind Energy, DTU Wind Energy Frederiksborgvej 3994000 Roskilde, Denmark, I-0092, 2013.

[5] J. Galvan, M. Sanchez-Lara, I. Mendikoa, V. Nava, F. Boscolo-Papo, C. Garrido-Mendoza, J. Berque, P.-M. G. and R. Rodriguez-Arias, "Definition and Analysis of NAUTILUS-DTU10 MW Floating Offshore Wind Turbine at Gulf of Maine. Experiments at Sintef O," Tecnalia R\&I, Derio, Basque Country, Spain, Public TRIORE-PUB-001/2017, Dec. 2017.

[6] W. Yu, K. Müller and F. Lemmer, "LIFES50+ D4.2: Public Definition of the Two LIFES50+ 10MW Floater Concepts," 2018. 
[7] P. Gomez, G. Sánchez, A. Llana, G. Gonzalez, J. Berque and G. Aguire., "LIFES50+ D1.1: Oceanographic and meteorological conditions for the design," 2015.

[8] M. Hansen and L. Henriksen, "Basic DTU Wind Energy controller," DTU, Department of Wind Energy, DTU, Denmark, E-0028, 2013.

[9] A. Krieger, G. K. V. K. Ramachandran, L. Vita, P. G. Alonso, G. G. Almeria, J. Berque and G. Aguirre, "LIFES50+ D7.2 Design Basis," 2015.

[10] J. Jonkman and M. Buhl, FAST User's Guide., NREL: Golden, CO..: NREL/EL-500-38230., 2005.

[11] J. Jonkman, Dynamics Modeling and Loads Analysis of an Offshore Floating Wind Turbine., NREL/TP-500-41958: NREL: Golden, CO., 2007.

[12] "The NAUTILUS-DTU10 MW Floating Offshore Wind Turbine Project site," Tecnalia R\&I; Offshore Renewable Energy Area, 3 April 2018. [Online]. Available: https://www.researchgate.net/project/NAUTILUSDTU10-MW-Floating-Offshore-Wind-Turbine-at-Gulfof-Maine.

[13] J. Jonkman, "Overview of the ElastoDyn structuraldynamics module, NREL Wind turbine modelling workshop, Bergen, Norway, 11-sep-2014.".

[14] D. Laino and A. Hansen, "AeroDyn user's guide," version 12.50. 2002.

[15] M. Hall, "MoorDyn User's Guide," University of Maine, 2014.

[16] A. Saltelli, K. Chan and E. M. Scott, Sensitivity analysis, Wiley New York, 2000.

[17] F. Pianosi, K. Beven, J. Freer, J. W. Hall, J. Rougier, D. B. Stephenson and T. Wagener, "Sensitivity analysis of environmental models: A systematic review with practical workflow," Environmental Modelling \& Software, vol. 79, pp. 214-232, 2016.

[18] B. Iooss and P. Lemaitre, "A review on global sensitivity analysis methods," in Uncertainty management in simulation-optimization of complex systems, Springer, 2015, pp. 101-122.

[19] C. Xu and G. Z. Gertner, "A general first-order global sensitivity analysis method," Reliability Engineering \& System Safety, vol. 93, no. 7, pp. 1060-1071, 2008.

[20] K. Müller and P. W. Cheng, "Application of a Monte Carlo Procedure for Probabilistic Fatigue Design of Floating Offshore Wind Turbines," Wind Energy Science, 2018.

[21] J. Sacks, W. J. Welch, T. J. Mitchell and H. P. Wynn, "Design and analysis of computer experiments," Statistical science, pp. 409-423, 1989.

[22] D. M. Hamby, "A review of techniques for parameter sensitivity analysis of environmental models," Environmental monitoring and assessment, vol. 32, no. 2, pp. 135-154, 1994.
[23] C. Hübler, C. G. Gebhardt and R. Rolfes, "Hierarchical four-step global sensitivity analysis of offshore wind turbines based on aeroelastic time domain simulations," Renewable Energy, no. 111, pp. 878-891, October 2017.

[24] P. M. McKay, R. Carriveau, D. S.-K. Ting and J. L. Johrendt, "Global sensitivity analysis of wind turbine power output," Wind Energy, vol. 17, no. 7, 072014.

[25] G. Li, H. Rabitz, P. Yelvington, O. Oluwole, F. Bacon, C. Kolb and J. Schoendorf, "Global sensitivity analysis for systems with independent and/or correlated inputs," The Journal of Physical Chemistry A, vol. 114, no. 19, pp. 6022--6032, 2010.

[26] S. Kucherenko, S. Tarantola and P. Annoni, "Estimation of global sensitivity indices for models with dependent variables," Computer Physics Communications, vol. 183, no. 4, pp. 937-946, April 2012.

[27] J. Helton, J. Johnson, C. Sallaberry and C. Storlie, "Survey of sampling-based methods for uncertainty and sensitivity analysis," Reliability Engineering \& System Safety, vol. 91, no. 10-11, pp. 1175-1209, October-November 2006.

[28] I. Dimov and R. Georgieva, "Monte Carlo algorithms for evaluating Sobol' sensitivity indices," Mathematics and Computers in Simulation, vol. 81, no. 3, pp. 506-514, November 2010.

[29] X.-Y. Zhang, M. Trame, L. Lesko and S. Schmidt, "Sobol Sensitivity Analysis: A Tool to Guide the Development and Evaluation of Systems Pharmacology Models," CPT Pharmacometrics Syst. Pharmacol., vol. 4, no. 2, pp. 6979, 2015.

[30] F. Campolongo, A. Saltelli and J. Cariboni, "From screening to quantitative sensitivity analysis. A unified approach," Computer Physics Communications, vol. 182, no. 4, pp. 978-988, 2011.

[31] A. Saltelli, A. Paola, I. Azzini, F. Campolongo, M. Ratto and S. Tarantola, "Variance based sensitivity analysis of model output. Design and estimator for the total sensitivity index," Computer Physics Communications, vol. 181, no. 2, pp. 259-270, 2010.

[32] M. T. Hagan and M. B. Menhaj, "Training feedforward networks with the Marquardt algorithm," IEEE transactions on Neural Networks, vol. 5, no. 6, pp. 989 993, November 1994.

[33] A. Pegalajar-Jurado, H. Bredmose, M. Borg, H. Andersen, T. Landbo and J. G. S. Straume, "State-of-the-art model for the LIFES50+ OO-Star Wind Floater Semi 10MW floating wind turbine. Under review," in DeepWind conference, 2018.

[34] R. Faerron Guzmán, K. Müller and P. W. Cheng, "Simulation requirements and relevant load conditions in the design of floating offshore wind turbines," Proceedings of the 37th International Conference on Ocean, Offshore \& Arctic Engineering, 062018. 